Exploring integrated independent learning and innovation in the Brazilian postgraduate programmes

\title{
Explorando a aprendizagem independente integrada e a inovação nos programas de pós-graduação brasileiros
}

\section{Explorando el aprendizaje autónomo integrado y la innovación en los programas de posgrado de Brasil}

Ronaldo Mota is a Visiting Professor at the Institute of Education of the University of London (Anísio Teixeira/CAPES Chair), retired Full Professor in Physics at the Universidade Federal de Santa Maria and carried out his Postdoctoral training at the University of British Columbia and at the University of Utah. Formerly, he was Secretary for Technological Development and Innovation, Secretary for Higher Education and Secretary for Distance Education at the Brazilian Government. E-mail: ronamota@ gmail.com.

\section{Abstract}

This paper presents remarks about integrated independent learning with emphasis on the role played by teachers in observing student learning experiences and in having the students share with the teacher the centrality of the teaching-learning process. This teaching strategy, applicable to any educational level, including graduate courses, is presented as a powerful contribution to the training of professionals, as it enables them to face the challenges associated with a new Brazilian scenario, wherein innovation and entrepreneurship are central priorities.

Keywords: independent learning, graduate programs, technological innovation, personalized self-instruction, entrepreneurship, innovation. 


\section{Resumo}

Este artigo apresenta observações sobre aprendizagem independente integrada, com ênfase no papel do professor, acompanhando as experiências de aprendizagem dos estudantes, e tendo os estudantes compartilhando com o professor a centralidade do processo ensino-aprendizagem. Essa estratégia de ensino, aplicável a qualquer nível educacional, inclusive aos cursos de pósgraduação, é apresentada como poderoso instrumento motivador para contribuir com a formação de profissionais capazes de enfrentar os desafios associados com o novo cenário brasileiro, em que inovação e empreendedorismo são prioridades centrais.

Palavras-chave: Aprendizagem Independente. Pós-Graduação. Inovação Tecnológica. Autoaprendizagem Personalizada. Empreendedorismo. Inovação.

\section{Resumen}

Este artículo presenta observaciones sobre el aprendizaje autónomo integrado con énfasis en el papel del maestro observando las experiencias de aprendizaje de los estudiantes, que comparten con el maestro la centralidad del proceso de enseñanza-aprendizaje. Esta estrategia de enseñanza, aplicable a cualquier nivel de educación, incluso a los cursos de posgrado, se presenta como una poderosa herramienta de motivación para contribuir con la formación de profesionales capaces de enfrentar los retos relacionados con el nuevo escenario brasileño, donde la innovación y el espíritu emprendedor son prioridades.

Palabras clave: Aprendizaje Independiente. Posgrado. Innovación Tecnológica. Autoaprendizaje Personalizado. Espíritu Emprendedor. Innovación. 


\section{The Brazilian scenario}

The Brazilian federation comprises the Union, 26 States, 5,564 Municipalities and the Federal District, in an area over 8.5 million km2, which represents almost half of the territory of South America. The population of almost 200 million inhabitants, mainly concentrated in the Southeast and Northeast regions, represent approximately $43 \%$ and $28 \%$ of the population, respectively (IBGE, 2012).

It is important to notice that the younger people, between 0 and 39 years of age, represent approximately $68 \%$ of the total population and the Brazilian age structure is changing in the last decades as a consequence of the reduction in the mortality and birth rates, as well as of the enhancement in the population's life span.

An intense industrialization process occurred between the fifties and the eighties and made the urban population quickly surpass the rural in the end of the sixties, in such a way that today the urban population represents more than $85 \%$ of the overall population.

Brazil is a land of contrasts, with both qualities and inequalities, making the task of providing education for all undoubtedly challenging. It is a country with a view for the future where education is concerned, wherefewareas were identified as key challenges for Brazilian education for the period of 2010-2020: raising teacher quality, protecting the early development of the most vulnerable children, building a worldclass secondary education system, maximizing the impact of federal policy on basic education and exploring links between innovation and education.

Nevertheless, in Education, despite the progress in many other areas, Brazil is still falling behind the average learning levels of other middle-income countries. It comes after Chile, Uruguay and Mexico when Latin America is concerned. Even considering that, there has been a sustained progress over the last decades in education (SANTOS, 2011). 
Brazil's progress is due to the massive expansion of schooling in the country in the last 15 years, and more recently to the quality targets that the federal government has established. The Brazilian Educational Development Plan (PDE - Plano de Desenvolvimento Educaciona), launched by the Ministry of Education in 2007 (MEC, 2007), has implemented a number of action programmes to enhance the quality of education, among them a digital inclusion programme, whose aims include the installation of microcomputers and multimedia labs in all public schools (130 thousand of them), and the production of multimedia digital content to support schools and students by creating an educational portal called Teacher' s Portal (Portal do Professor). In this context, the Brazilian Open University was also launched (UAB, in Portuguese: Universidade Aberta do Brasil, which aims at offering to teachers and learners increased access to digital resources, teacher training and educational content in a variety of formats (MOTA, 2008; MOTA and CHAVES, 2006).

Even with all these efforts, educational achievement has been the weakest link in Brazilian development and this is at the root of Brazilian inequality. In fact, it took four and half centuries for Brazilian education to develop. Very slow progress was achieved throughout the centuries and only in the second half of last century education started to show progress. Still, the present situation is not at all satisfactory.

A respectable segment of the Brazilian economy is modern and highly competitive, including manufacturing and especially agrobusiness. Then, it is possible to state that economy has gone much beyond the basic level, presenting a sophistication that has increased constantly, but, in general, the schooling levels have not responded at the same rhythm.

Concerning higher education, at around the middle of last century, Brazil decided to develop a network of public universities, associated with research and offering postgraduate courses, in order to prepare more lecturers for the increasing university system. During the sixties and seventies, at the same time that at least one federal university was implemented in each state, thousands of students 
were sent abroad for master's and doctorate degrees. On their return, in the seventies, research groups stated to be formed and hundreds of postgraduate programmes were launched giving origin to over thousands programmes today.

Regarding the Brazilian economy, over the past ten years the average GDP growth has been 3.2 percent and in 2010 the country had an impressive 7.5 percent growth rate. The Brazilian economy, led by the agricultural, manufacturing and mining sectors, is booming. As a direct consequence of the economic growth, from 2001 to 2009, poverty rates dropped from $35 \%$ to $21 \%$ of total population, although more than 40 million Brazilians still live below the poverty line.

In terms of market arrangements, Brazil is increasingly becoming a global player in a world where there is a clear overall tendency for tough international competition. To survive and do well, any contemporary country must worry a great deal about the levels of skills of its workforce and the qualities of the products and services provided.

Recently, Brazil has overtaken the United Kingdom's GDP becoming the world's 6th largest economy and the main issue today is whether such economic and social development will be sustainable. The answer is clearly associated to the quality of the provided education, the capability to produce knowledge and the amount of innovation that the country will be able to promote, connecting education and knowledge transfer from the scientific and technological communities to the productive sector.

Then, promotion of innovation and appropriate professional training, definitely, are becoming key strategies for a sustainable development, as defined in the New Economic Plan launched by the new President last year (MDIC, 2012), although the connections between education and innovation are still at the early stages concerning public policies. 


\section{The postgraduate programmes}

Brazil has experienced considerable growth in the number of higher education institutions during the last two decades, including private institutions (MOTA, 2011; MOTA, 2007). This spread of higher education in Brazil was achieved through active state support in order to provide equitable opportunities of higher education to all and it has been a proclaimed policy of the country to also encourage private investment in higher education, especially if the institutions are driven by charitable and non-profit motives.

Whilst universities have largely been in the public domain, Brazil has had a history of having a large number of colleges established and maintained by private management. In recent times, the private selffinancing colleges and other degree awarding institutions have gained prominence.

Basically, the higher education system in Brazil has been organized according to the European (French and Italian) tradition of academic schools, with the first universities being established during the 1930s. Even so, in spite of the recent expansion, only about $14 \%$ of the age cohort (18-24 years) is enrolled. Public higher education is free of fees, but enrolls less than $25 \%$ of the students. Quality is very uneven, both in public and private institutions, with a concentration of the scientific research still among the public universities.

The country has the most prominent system of postgraduate studies in Latin America. Enrolments have increased around $22 \%$ in the last five years totalling more than 165 thousand students distributed in around 2,800 programs - 2,500 at masters degree, 1,500 at doctorate level and almost 300 professional masters, graduating over 12,000 Ph.D., 40,000 masters and hundreds of professional masters students per year. Besides, the postgraduate programmes increase continuously without losing academic quality according to frequent evaluations.

Brazil has more than 80,000 researchers and scholars engaged in research at private and governmental institutions. These 
achievements result from 60 years of systematic and continuous investments in higher education by the Brazilian government, including the creation of the Brazilian Federal Agency for Support and Evaluation of Postgraduate Education, CAPES Foundation, established in 1951 within the Ministry of Education. CAPES is responsible to award scholarship grants to postgraduate students at universities and research centres in Brazil and abroad whose central purpose is to coordinate efforts to improve the quality of Brazil's faculty and staff in higher education. In 2012, CAPES supported about 22,000 students in Brazilian postgraduate programmes and 1,500 in other countries and, together with other agencies and the private sector, is responsible for the program Science without Borders aiming at sending 100,000 students and researchers abroad in the next four years, mostly concentrated in engineering and technological areas (CAPES, 2012).

The evaluation of the postgraduate programmes is conducted by CAPES, which uses an internationally recognized methodology. This evaluation system serves as the basis for the formulation of policies in the area of postgraduate studies and also as a tool for academic excellence in Brazil. Brazilian postgraduate programmes are evaluated every three years, with scores ranging from 1 (lowest) to 7 (highest). Programmes with scores of 3 or below are closely monitored by CAPES and consistently re-evaluated to improve deficiencies or close down the programmes.

Nevertheless, compared with the best international postgraduate programmes, generally, Brazilian postgraduate studies tend to be more academic in nature rather than professionally oriented and more concentrated in social and humanities, with less emphasis in engineering and technological areas (MOTA and MARTINS, 2008). Professional fields of study and career preparation are more commonly offered at the undergraduate level and even at that level there is a clear asymmetry, compared with international standards, in terms of percentage of social and humanities compared with engineering and technological careers. Also, the emphasis on academic achievements in the assessments does not stimulate the applied, technical and interdisciplinary programmes, especially those driven by demands from the productive sector. 
In Brazil, there are hundreds, maybe thousands, of postgraduate programmes that can match international counterparts. These programmes are linked directly to the creation in the 50's of two national agencies, CAPES and the National Council for Scientific and Technological Development, CNPq. The first one, as mentioned before, is more dedicated to funding and evaluating post-graduation programmes and the second mainly concerned with funding scientific research at universities and research centres. There are other funding agencies, such as the government's Financing Agency for Projects \& Studies-FINEP, with more emphasis in technology and knowledge transfer to industries, and many state research foundations, among them the FAPESP, the most effective one belonging to the richest state in the country, São Paulo.

As a consequence of the characteristics observed before, the financial relationship between the programmes and the local industries is minimal compared with other countries with similar academic systems. For a long time, Brazilian companies, concentrating on short term profits, based on imported technologies and dependent of the financial market, have considered long term investments quite unattractive. However, these trends are changing and moving very quickly. In fact, the economic globalization and the new role played by the country in the international scenario are making the Brazilian industries to face tougher competition and with the inflation under control they can no longer depend on profits from capital markets, as it used to be.

\section{Innovation and entrepreneurship}

Educational institutions, as well as their postgraduate programmes, have increasingly played and expanded a central role in science, technology and innovation-based economic development and the roles of universities and research centres have evolved from performing conventional research and educational functions to serving also as an innovation-promoting knowledge hub. In particular, these changes are even more important in the context of recent state efforts 
to shift the region from a basic commodities exporter to an innovationdriven economy.

The traditional university, in general, looks backwards and it assumes itself as a storehouse or accumulator of old knowledge. On the other hand, the modern university sees itself as a generator of new terms engaged with the advancement of technological innovation and economic development in its region (YOUTIEA and SHAPIRA, 2008). In the context of innovation as a central issue, universities are simultaneously central generators, especially motivated by the external demands, and repositories of knowledge in our society. The way that knowledge is developed, disseminated and applied affects not only the cultural richness of the society, but also the global competitiveness. To meet the challenges of competitiveness appropriate policies are necessary to encourage and facilitate closer understanding and joint work between universities and the productive sector.

The trends in entrepreneurship in Brazil suggest that the country's efforts to boost its culture of innovation and entrepreneurship promise to sustain its growth in the coming years. All available data suggest that recent businesses play a crucial role in Brazil's economic and social future. Currently small and medium size-enterprises are responsible for $96 \%$ of the jobs in Brazil and comprise $98 \%$ of all companies in the country. These relevant changes reflect that an entrepreneurial mindset is flourishing among Brazilians and they will influence the educational institutions and their postgraduate programmes (MOTA, 2009).

The young people between the ages of 18 and 24 comprise $36 \%$ of the unemployed workforce and, for sure, to stimulate the entrepreneurial spirit is crucial for them. Many sectors in Brazil have recognized this and have been taking a number of steps to encourage entrepreneurs. Brazil seems quite aware of the impact of new, growing businesses not only on employment but also on innovation, and this is reflected in its efforts to support start-ups. For example, FINEP has launched a significant project to support start-ups, PRIME, which will distribute around $R \$ 65,000$ to enterprises focused on innovation. 
FINEP expects to help 10,000 innovative companies over four years, thereby creating 10 new jobs per each one directly generated by a start-up.

There are some evidences that the universities are playing an important and necessary role in the country's entrepreneurial and innovation ecosphere. University-based incubator programmes are flourishing. According to the World Bank's sponsored Infodev partnership of aid agencies (INFODEV, 2012), 75 percent of companies supported by incubators are still operating three years later.

The presence of start-ups through the enterprise incubators inside the universities brings as a consequence a relevant integration between the undergraduate and postgraduate programmes. Student participation on the enterprises simulation as integrant part of the curriculum is becoming an important practice, as well as the approaches including case studies and problem-solving by external demands as central motivation for masters dissertations and doctoral thesis themes.

In accordance with APROTEC (ANPROTEC, 2012), Brazil's incubator network has developed from 136 in 2000 to over 500 today. The country leads one of the most successful incubation movements in Latin America, with incubator models that are bottomup, service-oriented, suited to regional needs, having universities as their facilitators. The new regulatory legal framework, including the Federal Innovation Law (2004) and the Good Will Law (2005), has also contributed to build other programmes over the past six years that focus on technological innovation, such as the government's efforts to recognize the importance of universities in the entrepreneurial ecosystem by passing a law that grants university professors temporary leave to create a start-up. It also provides tax exemptions for innovative enterprises.

Concerning the difficulties to start new enterprises in Brazil, there is a lot of room for improvement in the policy realm. Brazil's Ease of Doing Business rank in the World Bank's Doing Business project is 129 
out of 183 economies (WORLD BANK, 2012). Starting a business there takes 120 days, double the average for Latin American and Caribbean countries, and far worse than the average 13 days for OECD countries. Brazilian entrepreneurs also face a complex tax system and difficulties in the access to finance. Moreover, entrepreneurship education is lagging behind, according to Endeavour Brazil (ENDEAVOUR, 2012), by showing that only less than $10 \%$ of Brazilians aged 1864 receive any type of entrepreneurship education.

Brazilian entrepreneurs are starting also to address the needs of this marginalized population. Throughout the country, entrepreneurs are exploring market-based solutions to poverty issues, including access to quality education, affordable housing, health care services, and information technology.

Entrepreneurs in Brazil have a vast market of up to 200 million people with growing purchasing power. The middle class is becoming huge, just reaching more than 30 million people, having moved from classes $D$ and $E$ since 2003. The projection for the richer classes ( $A$ and $B$ ) is that in two years it is predicted to include more than 30 million people making the country a hotbed of opportunities. As a consequence, the new scenario is not only suitable for business opportunities in general but also it will demand quality education and research centres compatible with the capital needed to translate the produced knowledge into high-growth technological enterprises.

Brazil is increasingly embedded in a world where the traditional importance of manufacturing and the production of goods have been overtaken by the production, transmission and consumption of information and technology. Education could be expected to be one of the leading areas of society where these technology-based changes would take place. Although, in fact, many other areas have been affected more and faster than education.

This relative distance between education and the productive sector has contributed to keep using the same educational models without taking into account that our students have changed a lot. Our educational system is no longer fitted to teach them. 


\section{Education and innovation}

The relationship between education and innovation has been a complex and rich theme, especially with respect to the impact of new technologies (Selwyn, 2011). Even, with plenty of room between the exaggerated enthusiasm, based on the uncritical acceptance, and the prejudice and the automatic rejection, the debates have been characterized by two extreme behaviours.

To better understand the "in progress" incorporation of digital technology into the classroom, it is very helpful to remember the previous promises, the false expectations, as well as the success and achievements, of the last century's older cousins" like for instance movies, radio and television.

About educational films, Thomas Edison predicted at the beginning of the 1920s that the motion picture should be destined to revolutionise the educational system and that it would supplant, if not entirely substitute, the use of textbooks (CUBA, 1986). Just 30 years later, it became clear that films were not having a major impact on education, despite their huge popularity as an entertainment activity.

Radio, following the movies, also was launched as the great new technology able to change radically the educational system, allowing to be transmitted to a large number of students, in the most remote areas, at negligible cost. However, again, a few decades later, it was easy to realize that, despite a few cases of success, the overall impact was quite modest compared with the original expectations.

Education television, following movies and radio, was also supposed to replace definitely the chalk and talk model of teaching and learning. Especially during the 1970s and 1980s, a number of experiences, few of them with substantial success, were launched everywhere, including in Brazil (BUCCl, 2000). But, again, the chalk and talk" survived.

These new technologies were in general in fact incorporated and in localized cases with success, nevertheless, without the expected 
impact by the pioneers. The reasons for the relative failures were many, including cost of the equipments, the general lack of teachers' specific training, the relative incompatibility between content and the school curriculum, sometimes the low quality of programmes and, not less important, the eventual teachers' resistance associated with the introduction method in a top-down manner.

All these previous experiments help us to realize that social problems, where education is embedded, are much more complex and beyond the technological solutions. Also they contribute to prepare us to understand what is going on with the more recent digital technology wave nowadays. Even so, contemporary educational technology may present more positive results than its predecessors. The main reason is that we are facing now a convergence of all those media, where a modern device can be much more interactive, as well as time films, radio, television and computer conjugated with telephone, camera, localization instrument, games machine etc.

It is relevant to observe that it is a characteristic of technologybased education in general to see the learner at the centre of the learning process, allowing the students to choose the information and the timing appropriates to their particular demands and possibilities. Then, despite being reasonable to raise suspicious about the real potential to modify traditional education, digital technologies can be understood as a real new opportunity to be much more centred on the individual needs and absolutely appropriate for independent learning approaches.

All these phenomena lead us to think more carefully about the relationship between innovation and education and the appropriate learning approaches that must be stimulated. In this paper, integrated independent learning is presented as one of those possibilities able to face this new reality where new technologies are opening fresh opportunities in a scenario where innovation and entrepreneurship are central. 


\section{Independent learning}

In fact, there are no teaching and learning methods or approaches that will be the most appropriate always and applicable everywhere, independently of the circumstances. On the contrary, the specification will depend on each specific learning environment, including, among other variables: the adopted theory of learning, the resources and technologies necessary and the relationships established between teacher-student, as well as student-student (MEYER, I.L. et al., 2008).

The teaching and learning approach, in general, involves many processes like: a) modelling, based on imitation; b) feedback, comparing the performance with a standard; c) instructing, requesting specific actions; d) questioning, requesting a verbal response; e) cognitive structuring, providing explanations; and f) task structuring, sequencing a task into or from components. The different levels and the mixture of the processes above, together with other ingredients, will allow a greater degree of personalization in the learning process.

Just as examples, it is possible to list a general teaching and learning mechanisms, as follows: i) observation, where the teacher performs the action which the learner is required to imitate in the classroom and later in the context of application; ii) coaching, with the focus whilst the learner practices after the step of modelling; iii) goalorientated learning and anticipation, associated with three actions: at the beginning setting learning goals and providing learners with a model to start the task, at the middle monitoring their progress and at the conclusion providing an overall assessment of their goal progress; iv) mentoring, usually conducted face-to-face and involving a relationship between two people, where one is considered to have greater knowledge or experience; v) peer learning, the assumption made is that the learning relationship is between equals; vi) simulation, here the purpose is to simulate a real event, allowing the persons taking part to explore and understand the process, enhancing skills and performances; vii) instruction, nine related events are suggested: 1.teacher gains the attention of the learners, 2.then informs the 
objectives of the learning exercise, 3.stimulates recall of prior learning, 4.presents the content carefully structured, 5.teacher provides help attuned to the student current state of understanding and the student performs the task independently, after the level of support is gradually withdrawn until the student takes increasing control to perform the task; 6.performing relating to the institutional objectives; 7.feedback provided by comment on the student's performance allowing corrective action; 8.the new performance is assessed to determine if the desired performance has taken place; and 9.students then apply that knowledge in appropriate ways; viii) concept formation, it focuses in the re-forming of conceptual schema that the learner has about the world, where the learner has to absorb some of the ideas he is presented with and partially discard others; ix) reflection, it is based on the belief that deep learning comes from a sequence of experience, reflection, abstraction and active testing; $\mathrm{x}$ ) meta-cognitive learning, it refers to the learners' awareness of their own knowledge and their ability to understand, control and manipulate their cognitive processes; xi) problem-solving, the learners find out for themselves rather than being given answers to problems and they are required to engage in a series of interrogative processes with regard to texts, people and objects in the environment and come up with solutions to problems. Here, the learning resides in the process rather than in the end-product; and xii) practice, it is the act of rehearsing a behaviour over and over again or engaging in an activity again and again, reinforcing, enhancing the learning associated with the activity.

One characteristic of the world where innovation is central is the role played by the new technologies, especially digital technologies, including the internet. They present the great advantage of allowing the student, as well as the teacher, to develop their tasks much beyond the physical environment of the class room, widening access to education in such a way that we have never experienced so far.

Even so, as well pointed out by Selwyn (2011), these new circumstances demand a more careful thinking about the relationship between education and technology, trying to move beyond commonsense assumptions and exaggerated expectations and developing a 
more socially serious analysis of education and technology. In this case, the term technology nowadays refers to far more than just machinery and artefacts, including also social contexts and social circumstances.

It is a fact that digital technologies can also be seen as allowing an individualized way of doing things in everyday life. In this sense, internet has changed the patterning of everyday life, which includes the way we study, work, shop, meet people etc. Internet and other digital technologies can be seen as associated with constructivist forms of learning, as observed by Selwyn (2011). The reason is that, as internet, the constructivist view, including independent learning approach, sees the learning process as taking place as social progress of collective knowledge construction.

With respect to independent learning approach, this is one of the cases where the expression has been used to refer not always exactly to the same idea, since this term has been applied in very contrasting circumstances (open learning, study by yourself, resourcebased learning, hands-on, problem-based learning, home-schooling etc.). But, there is always a common reference to learner-centred methods, where learners are understood as individuals with individual needs and rights (PRINTRICH, 2000).

The particular approach named Integrated Independent Learning has as a special characteristic an emphasis on the role played by the classroom teachers along the student learning experience. In this sense, it is integrated to the curriculum and the students share with the teacher the centrality of the teaching-learning process. Learner autonomy is a key concept and the teacher is also a relevant factor along the process. It is supposed to be able to be applied in any level, including courses of postgraduate programmes, even considering that there are peculiarities associated with this specific level.

Nevertheless, for sure, these teaching procedures, like strong stimulation to study in advance before the classes and the necessity of one specific electronic site for each course, will enhance the skills associated to form professionals able to face the challenges of a 
world where innovation is a key factor, independently of the other aspects involved on producing and transferring knowledge. Even for postgraduate students it is relevant to lead them to consider the importance to reflect about the fact that we are dealing with a new reality where it is not enough anymore to imagine that just because the teachers teach the students learn. Besides that, digital competence is an essential capability for everyday life and sine qua non condition to face the challenges of this increasingly connected world.

Other learning approaches that have increasingly becoming of interest for the higher education sector are the problem-based learning (SANGUR and TEKKYA) and the work-based learning (BRENNAN and LITTLE, 2006). Work-based learning is a way by which it is possible to support the personal and professional development of students who are already at work and the focus of learning tends to be on the student's workplace activities. Learning through work, although still an unfamiliar concept in Brazil, is a concept emerged in the United Kingdom more than 20 years ago as a scheme for making higher education more accessible to adult workers (MAIA, 2008).

There is a set of skills (for instance: study in advance, workbased learning, hands-on, time-management, information technology uses, interpersonal skills, enterprise incubators etc.) which can be learned and applied in self-direct learning. I do believe that many of our students have an inborn capacity which is (at least partially) suppressed (or unexplored) by traditional education approaches and methods.

The main skills required for independent learning can be summarized as:

cognitive skills: including memory, attention and problemsolving. Students need to have reached a certain level in their cognitive development, such as being able to decode basic information as they embark on independent learning, and the teachers must be able to promote this cognitive development to sustain independent learning; 
meta-cognitive skills: associated with an understanding of how learning process occurs, allowing the students to internalize how they learn and also indentify the environment and resources necessary to help them with their processes, as well as being able to self-assess their learning;

motivation: is considered the most important effective skill being directly associated with increased independent learning and can also be an outcome of independent learning;

persistence: learning to face difficulties and developing skills to try again even after initial difficulties, making themselves able to persist with an eventual delay of gratification;

role played by teachers on promoting independent learning: students need to learn how to learn, indicating the effective ways to learn, which demands a new role for teachers, based not on the traditional transmission of information, but on process-oriented teaching, which ensures that students are actively involved in the learning process; and

previous preparation of the material to be taught: previous preparation is essential and determinant of the possible success of the method. It is directly associated with the study in advance technique.

This approach has as one of its reference the Keller Plan (KELLER, 1968), with all the necessary changes and adaptations, which can be seen as a reinterpretation taking into account a new reality of information and communication technologies and other new tools available today, as described below.

The Keller Plan is one type of personalized instruction in which learning materials are presented in small units. When a student feels ready, he or she takes a test on the completed unit and, depending on the result, is exposed to the main classes, continuing on the other units at a comfortable pace. Under the Keller Plan, instructors serve only as facilitators, administer no punishment at any stage of the learning, and award only pass or fail grades.

The Keller Plan, also called the Personalized System of Instruction (PSI), was mainly developed by Fred S. Keller with J. Gilmour 
Sherman, Carolina Bori, and Rodolpho Azzi, among others, in the middle 1960 s as an innovative method of instruction for the then new University of Brasilia.

As an application of Skinner's theories of learning, the PSI was conceived grounded on behaviourism and it should, in general, incorporate a few principles, which are considered the essential elements of the Keller Plan (ZIMMERMANN, 2002; PEAR and CRONETODD, 1999):

written materials: the primary presentation of a new content should be through written texts. Given the forms of media available at the time when the Keller Plan was developed (e.g., lectures, movies, audio records, television, radio, paper-based text etc.), paper-based texts gave students the greatest freedom; books and texts are portable, can be read at one's own pace, can be started and stopped at any time, can be easily reviewed, and can be marked by the reader. As an application of behaviourism, the Keller Plan was meant to maximize the number of operant behaviours that could be reinforced; this could best be done with written materials rather than have the learner be a passive observer of other media. Digital media available today could provide the same kinds of learner control and presumably could be incorporated in a contemporary implementation of PSI;

specific site for each course: to deliver the above written material and other functionalities, it is crucial for the appropriate development of this approach that each course design its own website where not only the subject and chronogram are made available but also work as a virtual environment for all students among themselves, the teacher and all other involved actors. The website should provide links easily accessible to supplementary material for previous or advanced levels, depending on the student's domain on the specific subject;

units of content: subject matter material should be broken down into separable, meaningful units. These units could have various kinds of relationships; for example, one could provide prerequisites for understanding a second, or the second could provide deeper elaboration of a proceeding unit. In any case, specific learning objectives should be definable for each discrete unit of content;

self-paced instruction: students should be allowed to advance 
through the course material at their own pace. While an instructor might specify the order in which learning units are completed, the learners should decide when and at what rate they learn. Learners could move through a course as quickly or slowly as they choose, as long they finish the whole schedule during the previously established period;

unit mastery: students must satisfy a mastery requirement in one unit before proceeding to the next. Typically, a unit in PSI would have more than one equivalent form of assessment-for example, three quizzes of equal difficulty or three primary sources or data sets to be analyzed. Students must demonstrate mastery of a unit's objectives to a certain level of quality. If the student does not reach the threshold, he/she is redirected to unit materials (or supplements if provided) and then take an equivalent form of the unit assessment. From the point of view of behaviourism, demonstrating mastery and being allowed to continue to a subsequent unit was presumed to be reinforcing;

teaching assistances or proctors: teaching assistances or proctors are an important part of the Keller Plan. They could be external to the course (adults or peers brought to the course from external sources) or internal (advanced students in the course who are doing well, have completed all units to date, and have good interpersonal skills). They are the arbiters of unit mastery; they would certify mastery, discuss areas of weakness, and direct students to the next units; and

main classes: for each unit of content, a main class should be provided by the teacher in charge to those students able to attempt. It is a special moment where the teacher will interact directly about the planned unit with the students having as guarantee that all of them have already demonstrated initiatives to know about the subject to be taught and making efforts in direction to explore the self-instruction process until the upper limit.

The Keller Plan has mainly been used in higher education, particularly as a more personalized form of instruction in large classes, but there is nothing inherent in Keller's formulation to restrict its application to particular grade levels, content or type of courses. There has been a good deal of research on the effectiveness of PSI, which indicated that, with great caution concerning the not desirable so strong behaviourist influence and appropriate customization, it has 
had robust, significantly positive on learning when compared to more traditional lecture-based formats (PEAR and CRONE-TODD, 1999).

\section{Conclusions}

Integrated independent learning has as a special characteristic an emphasis on the role played by teachers while observing students learning experiences, being integrated to the curriculum and having the students sharing with the teacher the centrality of the teachinglearning process. This educational approach has been presented and analyzed as very helpful for the necessary reorientation of the traditional adopted teaching methodologies. The relationship between education and innovation has been explored with respect to the impact of the digital technologies, which permit to see the learner at the centre of the learning process, allowing the student to choose the information and the timing appropriates to particular demands and possibilities. The stimulation to study in advance, enterprises incubators, problem-based learning, work-based learning, hands-on procedures, Keller Plan, as well as others techniques here presented, must be seen just as possible examples among many other initiatives that could help to improve the independent learning approach, which can be adapted respecting the peculiarities and circumstances of the specific educational level.

The trends in entrepreneurship in Brazil suggest that the country's efforts to boost its culture of innovation and entrepreneurship promise to sustain its growth in the coming years. To face this reality, where new technologies are opening fresh opportunities, integrated independent learning is presented as a possibility for an appropriate teaching strategy applicable to any educational level, including postgraduate courses, which could act as powerful motivators to contribute to the training of professionals compatible with the challenges associated with a new scenario where innovation is central.

Received 23/04/2012

Approved 26/10/2012 


\section{Acknowledgments}

I would like to thank Dr. Maria de Figueiredo-Cowen and Professor David Scott, from the Institute of Education, for their valuable contributions. This work was supported by CAPES-Brazilian Agency, through the Fellowship Cátedra Anísio Teixeira.

\section{References}

ANPROTEC. Portal. Available in: http:/ /www. anprotec.org.br. Access in: April, 2012.

\section{BRENNAN, J.; LITTLE, B. Towards a Strategy for Workplace Learning} Report of a study to assist HEFCE in the development of a strategy for workplace learning. London: Centre for Higher Education Research \& Information, 2006.

BUCCl, E. A TV aos $\mathbf{5 0}$ anos - criticando a televisão brasileira no seu cinquentenário. São Paulo: Fundação Perseu Abramo, 2000. (Veja também: http:/ / www.lendo.org/a-televisao-brasileira-e-seu-papelna-educacao-caso-tv-cultura/. Acesso em: abr. 2012).

CAPES. Portal. Available in: http:/ /www.capes.gov.br. Access in: April, 2012

CUBA, L. Teachers and Machines: the Classroom Use of Technology since 1920. New York: Teachers College Press, 1986.

ENDEAVOR. Portal. Available in: http://www.endeavor.org.br. Access in: April, 2012

IBGE. Portal. Available in: http:/ /www.ibge.gov.br. Access in: April, 2012.

INFODEV. Portal. Available in: http:/ /www.infodev.org. Access in: April, 2012 
KELLER, F. S. "Good-bye Teacher...". Journal of Applied Behaviour Analysis, v. 5, p. 79-89, 1968.

MAIA, C. Work-based Learning: a nova geração do e-learning. Rev. Diálogo Educ., v. 8, п. 24, P. 459-472, 2008.

MDIC. Portal. Available in: http:/ /www.brasilmaior.mdic.gov.br. Access in: April, 2012.

MEC. Portal. Available in: http:/ / portal. mec.gov.br/arquivos/livro/index. html. Access in: April, 2012.

MEYER, B.; et al. Independent Learning. Literature Review. Research Report DCSF-RR051. Department for Children, Schools and Families. Learning and Skills Network, 2008.

MOTA, R. Educação Superior: Assunto de Estado e Prioridade Social. Ensino Superior Particular Brasileiro, p. 287-295, 2007.

A Universidade Aberta do Brasil. In: LITTO, F.; FORMIGA, M. (Eds.). Educação a Distância: 0 Estado da Arte. São Paulo: Pearson Prentice Hall, 2008. p. 297-303.

Inovação Tecnológica: Desafios e Perspectivas. Educação Brasileira, v. 31, p. 61-80, 2009.

Novos Tempos, Espaços e Públicos: Os Complexos Desafios da Educação Superior no Brasil. Interesse Nacional, v. 2, p.77 87, 2009.

O Papel da Inovação na Sociedade e na Educação. In: COLOMBO, S.; RODRIGUES, G. M. (Eds.). Desafios da Sociedade Contemporânea. p. 459-474. Porto Alegre: ARTMED, 2011.

MOTA, R.; CHAVES, H. Universidade Aberta do Brasil e Perspectivas da Educação a Distância no Brasil. Educação on Line, p. 459-474. São Paulo: Edições Loyola, 2006. 
MOTA, R.; MARTINS R. O. A Política do MEC para Educação Superior e Ensino de Engenharia no Brasil. Revista de Ensino de Engenharia, v. 27, p. 52-68, 2008.

PEAR, J. J.; CRONE-TODD, D. E. Personalized system of instruction in cyberspace. Journal of Applied Behavior Analysis, v. 32, p. 205-209, 1999.

PINTRICH, P. R. The role of goal orientation in self-regulated learning. In: BOEKAERTS, M.; PINTRICH, P. R.; ZEIDNER, M. (Eds.). Handbook of Selfregulation, p. 451-502. San Diego: Academic Press, 2000.

SANGUR, S.; TEKKAYA, C. Effects of Problem-Based Learning and Traditional Instruction on Self-Regulated Learning. The Journal of Educational Research, v. 99, n. 5, p. 307-320, 2010.

SANTOS, A. I. Open Educational Resources in Brazil. State-of-the-Art, Challenges and Prospects for Development and Innovation. Report UNESCO/ Institute for Information Technologies in Education. Russia, 2011.

SELWYN, N. Education and Technology. Key Issues and Debates. London: Continuum Int. Publ. Group, 2011.

WORLD BANK. Portal. Available in: http://doingbusiness.org/data/ exploreeconomies/brazil. Access in: April, 2012.

YOUTEIA, J.; SHAPIRA, P. Building an innovation hub: A case study of the transformation of university roles in regional technological and economic development. Research Policy, v. 37, p. 1188-1204, 2008.

ZIMMEMAN, B. J. Becoming a self-regulated learner: an overview. Theory into Practice, v. 41, n. 2, p. 64-72, 2002. 